\title{
Family Preface
}

\author{
Julia Sia Ing
}

No culture, not even the French, has been more concerned with cuisine than the Chinese. With an immodest amount of pride, and observation, I would add that no chef enjoyed preparing, cooking, and sharing Chinese food more than my mother, Mary Sia. She would be amazed at the longevity of Mary Sia's Chinese Cookbook, which the University of Hawai'i Press first published in ${ }_{195} 6$ and continued printing through three editions and multiple reprints into the I990s, decades after her passing. The family considers this an extraordinary honor to her memory, and we are thrilled to know that our mother's cookbook is available again. When the book was out of print, many people continued to ask the family where they could buy a copy. One friend found a copy for sale on Amazon.com for two hundred dollars. Mom would never have dreamt that her little spiralbound cookbook with the yellow and red cover would become a collector's item.

Mom's parents, Doctors Tai Heong Kong and Khai Fai Li, were both busy professionals, pioneer practitioners of Western medicine. In fact, my grandmother delivered so many babies, 6,000 in her fifty years of practice, that she was included in Ripley's Believe It or Not in I946. Her success is all the more remarkable considering her humble beginnings. As an infant, my grandmother was left in a basket on the steps of the Berlin Mission Foundling Hospital in Hong Kong. Scribbled on a slip of paper was her only identification: Kong Tai Heong (River of Elegant Fragrance). Throughout her life, she treated all who came to her, whether they paid with money, chickens, or garden vegetables, or not at all.

My grandmother's unstinting service to others often left my mother, as the eldest daughter in a family of nine children, with a lot of responsibility. As a child, Mom spent many happy hours in the kitchen with the family cook, Ah Pak Po, learning to cook southern Chinese family dishes. Later, living in Peking, Mom discovered the northern style of Chinese cuisine and added it to her culinary repertoire. With her usual enthusiasm, she entertained Hawai'i visitors and university students studying in Peking, friends in her international women's clubs, American expats living in Peking, American embassy dignitaries, and fellow faculty and wives of Peking Union Medical College. She organized restaurant groups, taught friends how to cook favorite dishes, and published her first book, Chinese Chopsticks (I935), a slim volume with recipes and restaurant recommendations. 


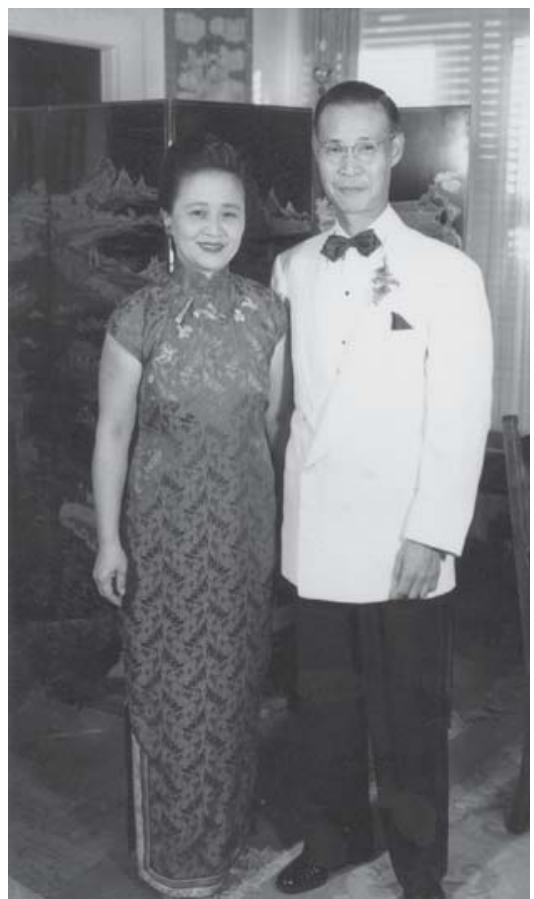

Mary and Richard Sia
My parents were accomplished musicians. In fact, that is how they first met. At a Chinese Christian students' conference at Brown University in I923, my father was a solo vocalist and my mother was assigned to accompany him on the piano. He took double notice when she won the women's athletic competitions at the conference. He proposed five days later, and they married within a month and a half.

As children, my sister Sylvia Tsai, brother Calvin, and I were surrounded by music, the aromas of good food, and the love of our parents and beloved Amah, who was like a second mother to us. I have many happy memories of our time in Peking. I recall looking out the second-story window of our house, watching happenings in the neighboring courtyards in the hu tungs (alleys). I so clearly recall a funeral scene with everyone dressed in white and weeping. I

remember the peddlers, the roasted chestnut man, the hot roasted sweet potato man, and the knife sharpener, each calling out their wares and using a signature instrument to attract attention. My mother purchased the instruments, and brother Calvin demonstrated the calls and instruments in the Chinese cultural programs she organized for USO audiences during the World War II years. My sister Sylvia and I joined other young models showing the old collection of richly embroidered costumes. Cal, a retired pediatrician, highly honored for his established medical programs locally and nationally, still remembers the hu tung calls.

I was ten in I939 when we left Peking to escape the Japanese occupation of the city. I wished with all my heart that our beloved Amah could come to Hawai' $i$ with us. Leaving her was a great loss. I can still see the little red embroidered shoes with a lion's face at the toes that she gave me one Chinese New Year's eve.

At the end of the difficult journey out of wartime China, we were welcomed back to Hawai'i by my grandparents, who had a house waiting for us in the Bingham Tract neighborhood, the Chinese Hollywood of those days. My mother, happy to be home but sorry to leave a privileged life in Peking, plunged into a whirlwind of activities, sharing her love of music and food. She served for twelve years as church organist in China as had my father as choir director. Both continued volunteering at the First Chinese Church of Christ in Honolulu, Mom for 
another twelve years. When we became members of Central Union Church, she served as organist at Atherton Chapel as well. She extended her love of music by giving piano lessons to many children of friends, holding recitals at our home.

Food and entertaining were a great source of pleasure for Mom. For twentysix years she taught her popular cooking classes at the Honolulu YWCA and gave cooking demonstrations in Hawai' $i$, on the Mainland, and on television. As one of the annual Narcissus Festival events in Honolulu, her cooking demonstrations drew standing-room-only crowds at the Neal Blaisdell Concert Hall. In a touching tribute, the board of directors of the Richards Street YWCA named their third floor cooking facility "Mary Sia's Kitchen." To this day I meet people who tell me, "I remember your mother. I took her classes." Her classes were also very popular with wives of military officers serving in Hawai'i. Once one commanding officer's wife considered the experience worthwhile, it became "a must" for all the incoming young wives. I remember when a group of her students invited Mom to a dinner for which each had prepared one dish. She smiled all day thinking of the slicing, chopping, steaming, and frying happening at Makalapa, Pearl Harbor.

At the same time that Mom taught her classes cooking techniques, she introduced them to Chinese history, folklore, and customs. She showed them how to shop in Chinatown. Her sense of humor was part of her charm, and she would weave into the classes and demonstrations anecdotes of adapting to life in China.

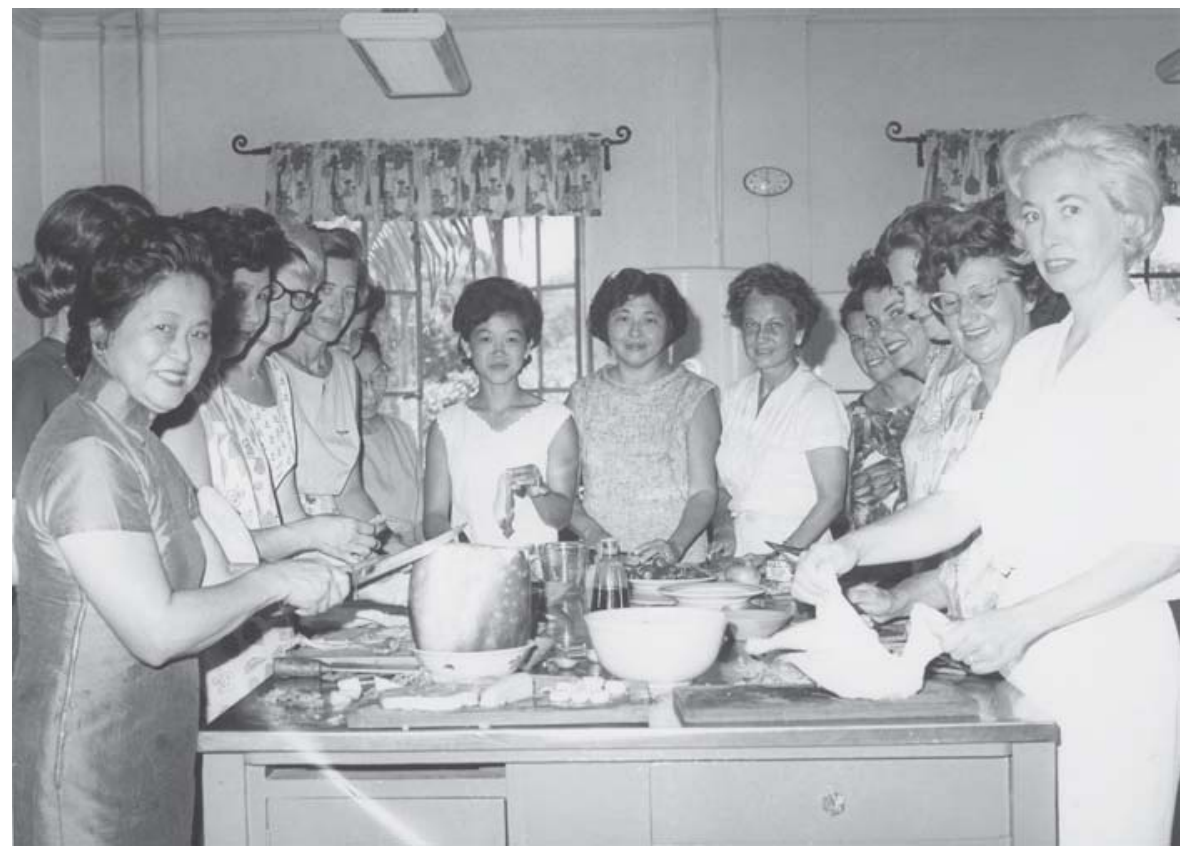

Mrs. Sia and the ladies of her cooking class 
One story she shared was about learning Mandarin and how, when she asked the houseboy to find her purse (p'i bau), she mistakenly asked him to find her "tush" (p'i $\mathrm{ku}$ ). She had the timing of an entertainer, and the stories always elicited laughter. I remember saying to her after one of her cooking demonstrations and classes, “Mom, I don't know how you do it!” She answered, "Julia, when you are comfortable with what you do, you do it easily."

When she entertained, she made her tables festive with her Canton porcelain and her slender silver chopsticks, silver wine cups, and silver soup spoons on little plates, all etched with the Chinese character for "Sia." The then-president of Punahou School, John Fox, once remarked that, though Mom's food was delicious, "It's impossible to eat with your silver chopsticks." Forks were always offered on request. Formal meals consisted of nine courses featuring a variety of contrasting tastes, textures, colors, and differing preparations. In China we had servants to assist with preparation; in Hawai'i my sister Sylvia and I were recruited to help, peeling and de-veining the shrimp and stuffing won tons. My fingers were stained brown, like a smoker's, from peeling the membranes off soaked walnuts. We found cooking a chore; her joy was not contagious.

There was always a pot of tea kept warm by the tea cozy. When someone asked my mother how she retained her youthful vigor, she said, "I drink tea, and I eat a lot of ginger." She had so much energy and so much love. I remember her healthy, fortifying steamed chicken and ginger broths, her sweet-sour pig's feet with eggs poached in a delicious gravy, her beef, ginger and red dates broths, all prepared for us when we were ill and when I was a new mother.

The family called Mom "the Julia Child of Hawai'i." The summer before she passed away in I97I, my mother gave her last cooking lessons to my three daughters and their young friends, making sure that future generations sliced, diced, and fired up their woks with proper technique and a love for Chinese cooking. With the new edition of Mary Sia's Chinese Cookbook, my mother's aloha and culinary art continue to be shared. Bon appetit, or as Mom would say in Mandarin, "Ch'ing ch'ih." 